\title{
Sex-selective Abortions and Infant Mortality in India: The Role of Parents' Stated Son Preference
}

\begin{abstract}
In India, millions of female foetuses have been aborted since the 1980s alongside an abnormally high infant girl mortality rate; this has generated a vast literature exploring the root causes of son preference. The literature is sparse, however, on how the decisions to abort or neglect girls are made. This paper examines mothers' and fathers' respective roles behind those decisions. Using NFHS-3 data, we show that sexselective abortions are most commonly used if both spouses or if only the fathers prefer sons, while sex-selective neglect is used if only the mothers prefer sons.
\end{abstract}

Keywords: India, infant mortality, sex-selective abortions, son preference.

JEL: J12, J16. 


\section{Introduction}

Son preference is deeply ingrained in Indian culture. For example, in Tamil Nadu, it is not uncommon to name daughters Venda, meaning "don't want", and Podum Pennu, meaning "enough of daughters" (George 1997) and a common blessing to brides is "May you be the mother of a hundred sons" (lyer 2002), to take only two examples.

Many factors behind this son preference have been identified by the literature: the dowry system, practice of exogamy, cultural rules limiting married daughters' support to their natal family, caste system penalizing the brides' natal castes, inheritance rules, importance of having a son for securing a good afterlife and higher status given to mothers of sons than to mothers of daughters (see, for example, Das Gupta (1987), Das Gupta et al. (2003) and Dyson and Moore (1983)). ${ }^{1}$

While in the past parents preferring sons had to rely on sex-selective neglect or outright infanticide to obtain the desired sex-ratio among their children, the advent of ultrasound and amniocentesis since the early 1980s now allow them to sex-selectively abort daughters, reducing drastically the emotional and physical cost - in terms of depletion of the mother's health - of engineering the sex-ratio among their children.

Given the strong son preference prevalent in India, this capacity to obtain the desired sex-ratio among one's offspring contributed in a sharp decrease in the overall sex-ratio among children less than six years old - from 976 girls per 1000 boys in 1961 to 914 girls per 1000 boys in 2011 (census data).

However, despite the availability of drastically less costly methods, some parents still rely on sex-selective neglect and infanticide to obtain their desired sex-ratio. This paper sheds some light on this conundrum using data from the third National and Family Health Survey (NFHS-3) conducted in 2005-2006. 
We argue that the coexistence of sex-selective abortions - a relatively low cost method - alongside sex-selective neglect and infanticide - relatively high cost methods originates from diverging son preference among spouses.

The literature is generally silent on the role of fathers in the decision to eliminate female foetuses/children. Indeed, it is generally taken for granted that the main decision-makers when it comes to children are the main care-givers, the mothers. However, given the importance of children in one's life, it would be surprising if fathers have no opinion or say in major decisions concerning them. This is likely to be particularly true regarding the gender of a child in societies that consider having a son to be of primordial importance.

Focusing on women's preference is not a problem if the couple agrees on the desired sexratio. However, about $30 \%$ of the couples in our sample have diverging preferences. For couples that have diverging son preference, we postulate that the control of financial resources, mobility and the control of care-giving resources will determine how preference for sons is implemented. To test this hypothesis, we analyse the effect of household types - that is, both prefer sons, only the father prefers sons, only the mother prefer sons or neither prefer sons - on the probability of a child to survive infancy - a measure of sexselective discrimination -, on the sex-ratio among the couple's offspring and on the probability that the last birth was a boy - to proxy for sex-selective abortions. While we do not have direct measures of sex-selective neglect leading to death and sex-selective abortions, we rely on the fact that the natural infant mortality rate and the natural sex-ratio at birth among human population are well-known and stable. Thus deviance from the natural range can be used to proxy for sex-selective neglect leading to death and sexselective abortions. While it is true that other factors may lead to small differences from the normal range, for example, the prevalence of Hepatitis $B$, the impact is very small (see 
for example Drew et al. 1978) and cannot explain the results we found. It would only be if girls' births are under-reported that we may end up with a sex-ratio at birth outside of the normal range without pre-birth sex determination taking place. To limit the extent of this problem, the birth history was collected with great care to make sure that all births were recorded (IIPS, 2007a, b). Nevertheless, we carry robustness checks to ascertain that our results are not driven by underreporting of girls' births.

Our results show that couples who share a preference for sons are the most likely to resort to sex-selective abortions, followed by couples where only the husband prefers sons; whereas, in couples where only the wife has a preference for sons, sex-selective neglect is prevalent, a technique not commonly used in any other household type.

The remainder of this paper is organized as follows. The theoretical links between spouses' stated son preference and control of resources with sex-selective abortion and infant mortality are developed in section two. The theory is then brought to the data

using NFHS-3. Section three introduces the dataset and discusses the empirical strategy while results are presented in section four. Concluding remarks are presented in section five.

\section{Theory}

The number and gender of children a couple has are their joint decisions. To maximise utility, parents will try to reach their ideal sex-ratio at the lowest possible cost.

The husband and wife try to converge to one preference (peer influence effect, Becker and Murphy (2000)) as they don't want the marriage to dissolve or, more likely in India, to become non-cooperative. This cooperation depends on their relative willingness to 
accommodate and can be attributed to feelings of altruism, with a spouse including his/her spouse's preference in his/her own utility. Another factor could be socialization as spouses are likely to spend time together and share thoughts and ideas.

However, if preferences do not converge the husband and wife bargain over sexselective abortion, if this is what he or she desires. The strength of bargaining would depend on the control of financial and non-financial resources in the household by each spouse.

If a parent was forced to accept the birth of an unwanted daughter, sex-selective neglect leading to death can be used as a final means to achieve the desired sex-ratio.

A formal model, following Becker (1960), on the number of children as an equilibrium solution to joint parental utility maximisation subject to income and cost constraint is available in Online Appendix A. Given the preference the number of children will be engineered to achieve the desired sex-ratio. This optimal number depends on control of financial resources, divergence between son preferences and cost - financial, emotional and time - of having children among the parents.

If preferences match perfectly, any undesired foetus will be aborted and desired pregnancies will be carried to term. If preferences do not converge, sex-selective abortions will take place only if the spouse with the strongest son preference is able to implement his/her preference despite the resistance of his/her spouse.

If one parent has been forced to accept the birth of an undesired daughter, as a last resort the child can be sex-selectively neglected, increasing the odds of death. As this method of implementing one's preference is the most costly, financially, emotionally and physically, this method should be implemented only as a last resort.

We argue that, while the relative bargaining power of spouses will vary from one 
household to the other, on average men with a strong son preference are more likely to be able to implement their preference than women with an equivalently strong son preference. The reason is that the financial resources necessary to implement an abortion as well as the freedom of movement necessary to go to the clinic are generally controlled by the husband, not the wife. However, women being the main care-givers, they are the most able to implement their preference post-birth. As infants are frail, small neglects, such as taking a little longer to treat diarrhoea or a fever, can easily cause death. Therefore, a mother desiring to eliminate an undesired daughter post-birth, can easily do so without her spouse necessarily noticing. On the other hand, as men in India often play only a minor role as care-giver to new-borns, very few will be able to get rid of an undesired daughter without their wife noticing.

In the next section we will be using data from NFHS-3 to test the following hypothesises:

1. Sex-selective abortions are more likely to occur when either both parents or the father alone prefer sons.

2. Post-birth solutions, that is, neglect leading to death, should occur when the mother alone has a preference for sons.

\section{Data, Descriptive Statistics and Empirical Strategy}

NFHS-3 data is used to empirically test our theory. In the selected households, all women aged 15 to 49 were interviewed. For a sub-sample of households, all men aged 15 to 54 were asked to answer a man-only questionnaire. A total of 74,369 men and 124,385 women answered the questionnaire, with a response rate of, respectively, $81.7 \%$ and $94.5 \%$ (IIPS 2007a, b). We are able to match husband and wife for 31,940 dyads. 
Pre-birth solutions - comprising mainly sex-selective abortions but also sperm sorting and other devices to alter child's gender at conception - are measured using the sexratio at birth $(33,641$ observations) and the gender of the last child. In this later case, the data set is limited to children born during the years of the survey (2005-2006) or the year before the survey (2004). Each child is matched with his/her parents, leading to a sample of 5,227 observations.

While the proportion of boys born should be around $51 \%$ without sex-selective abortions, the proportion in our data is higher at $53.4 \%$, implying that some sex-selection before birth is taking place. The ratio is even more skewed among the last birth with $54.7 \%$ boys. Post-birth solutions are proxied by infant survival. Each child aged between one and five years old or who died before the age of one is matched with his/her mother and father, leading to a sample of 11,060 observations. ${ }^{2}$ Neglect leading to death is more likely soon after birth as new-borns are frailer. Infant boys are particularly frail given the high presence of testosterone in the mother's uterus slows down the growth of the lungs, increasing the odds of dying of respiratory problems (Waldron, 1998). As a result, the natural sex-ratio of infant mortality is of 1,200 boys for every 1,000 girls (Balsara et al., n.d.). The Indian girls' relative risk of dying during infancy is, however, much larger than this figure in many states (Figure 1, Panel D).

The key explanatory variable, in all models, is the structure of stated son preference in the household. We define somebody has having a son preference if the respondent states that he/she desires more sons than daughters if he/she could start over his/her fertility history. 3

Based on NFHS-3 data, Indian men and women desire on average 1.16 and 1.15 sons per daughter, respectively. These numbers are much higher than the normal biological 
sex-ratio at birth, oscillating between 1.05 and 1.07 boys per girl, giving plenty of scope to parents to engineer the sex-ratio among their children.

This average, however, hides some important variations across India. The Southern states have overall much more gender equal preferences than the Northern states (Dyson and Moore, 1983) (Figure 1, Panels E and F).

Supporting the idea that stated son preference is correlated with gender discrimination, we observe the same pattern, with more discrimination taking place in the North than in the South, for education (Figure 1, Panel A), access to vaccination (Figure 1, Panel B), sex-ratio among children less than 6 years old (Figure 1, Panel C) and, to some extent, infant mortality (Figure 1, Panel D), to state only some examples.

[Figure 1 about here]

We take advantage of the fact that the sex-ratio among their children - alive or not cannot be determined by parents, other than via sex-selective abortions, sex-selective neglects or stopping behaviours (that is, to stop having children only when the desired number of sons has been reached). Hence, to quantify the level of sex-determination, we can simply look at the sex-ratio among children - alive or not, at the time of the survey - without any control variables other than the household types. Specifically, using OLS, we estimate:

$$
s r_{h}=w_{h}^{\prime} \kappa_{h}+v_{h}
$$

with $\mathrm{sr}_{\mathrm{h}}$, the sex-ratio among children in household $\mathrm{h}, \mathrm{w}$ a vector of stated son preference and v, the error term. 4 We allow for four types of households - households where both parents prefer sons, households where only the mother prefers sons, households where only the father prefers sons and, as the reference category, households where none of the parents prefer sons. 
While sex-selective abortion is the most cost-effective method to obtain the desired sexratio, when a parent is forced into accepting the birth of a daughter, sex-selective neglect, leading to death, or infanticide may be used. We thus estimate a model explaining the probability of surviving infancy. As the probability of surviving infancy depends on other factors than the structure of stated son preference, control variables for biological and socio-economics factors are included. Specifically, using a Probit estimator, we estimate:

$$
\mathrm{s}_{\mathrm{i}}=\mathrm{z}_{\mathrm{i}}^{\prime} \gamma+\mathrm{w}_{\mathrm{i}}^{\prime} \zeta+\delta_{\mathrm{i}}
$$

with, $s_{i}$, a dummy variable taking the value of 1 if a child $i$ has survived infancy, 0 otherwise; z, a vector of socio-economic and biological factors; w, a vector of stated son preference variables defined as before; and, $\delta$, the error term. ${ }^{5}$

\section{Empirical Results}

\subsection{Sex-Selective Abortions}

The most cost-effective method to eliminate unwanted daughters is to rely on sexselective abortion. While sex-selective abortion entails financial, physical and emotional costs, which may deter some parents to implement their son preference, those costs are fairly modest. Indeed, at between 250 to 1500 Rupees (5-30 USD) (Booth et al., 1994; and Vella, 2005) the financial cost of a sex-selective abortion is very low compared to the cost of raising and marrying off an unwanted daughter. Similarly, an abortion is unlikely to be as demanding physically as to carry a foetus to term and entails a much lower mortality risk (Ronsmans and Graham, 2006). We do not have a very good proxy for emotional cost; however, in India, abortions are fairly common - 6.5 million abortions were carried out in 2006 (Sinha, 2012) - and well accepted as a fertility control method. 
Therefore, for many parents, the emotional cost also will be relatively low.

Given its relatively low cost, parents with a preference for sons should use sex-selective abortion as their first choice method of implementing their preference. There are however good reasons to believe that not all parents willing to seek a sex-selective abortion will be able to do so. Indeed, to carry a sex-selective abortion one needs cash and the ability to go to an abortion clinic. We argue that for many women those two preconditions will not be met. Indeed, in our sample, $26 \%$ of women cannot take decisions alone regarding their own health, $92 \%$ cannot take a decision alone regarding large household purchase and $60 \%$ need to ask permission to visit family or friends. Moreover, despite the fact that the law does not require the husband's permission for a woman to undertake an abortion, Ganatra et al. (2001) find that in Maharashtra, a state with moderate patriarchal culture, $27 \%$ of women who underwent a sex-selective abortion had to provide their husband's written consent to their health provider. Thus, for many women, husband's agreement would be necessary to obtain a sex-selective abortion; agreement which is unlikely to be given if the husband does not share his wife's stated son preference. We thus postulate that sex-selective abortions will be more prevalent in households in which the father has a stated son preference, either alone or in conjunction with his wife.

The results for the model explaining the sex-ratio at birth are presented in Table 1. Looking at Column 1, we note that the sex-ratios are particularly skewed in households where both parents have a preference for sons, followed by households where only the mother has a preference for sons, then by households where only the father has a preference for sons and, finally, by households where none of the parents expresses a preference for sons. In the latter case, the sex-ratio is normal. All the coefficients are statistically significantly different from each other. 
Under-reporting of birth of girls is known to occur in India though NFHS reports careful attentiveness while collecting the data to ensure that all children are reported in the birth history (IIPS, 2007a, b). As a robustness check, to eliminate the risk of under reporting bias, the model was also estimated using the gender of the last birth, limiting the sample to children who were born in the last 3 years, making it less likely that the mother had time to forget the birth.

Moreover, our model may suffer from reverse causality since, as previously mentioned, it is possible that parents are influenced by the sex-ratio that they have at the time of stating their son preference. As long as we assume that this ex-post rationalization affects both parents in the same way, this bias would not change our key results. However, to be on the safe side, as a robustness check, we use the fact that the gender of the last child should not determine the stated desired sex-ratio as strongly as the gender of all children already born since the last child is one among many. ${ }^{6}$ Hence, we estimate the same model as before, but this time we use the gender of the last child born between 2001 and 2006 - as dependent variable. The conclusion remains as before, with the only exception that there is no more statistically significant difference between households where only the mother prefers sons and households where only the father prefers sons. Thus, the households that are the most likely to see the birth of a boy are those, in order, where both parents prefer sons, the father or the mother only prefers sons (those two coefficients are not statistically significantly different), followed, at last, by households where neither of the parents expresses a preference for sons (Table 1, Column 2).7 The limit of this approach is that parents may be more likely to stop child-bearing after the birth of a son, which inflates the sex-ratio among the last birth.

To deal with this issue, we limit the sample to births in the years of the survey (2005- 
2006) and the preceding year (2004). For that restricted sample, stopping behaviours should play a lesser role as the short time span makes it unlikely that more than one birth was carried to term. ${ }^{8}$ Reassuringly, we reach the same conclusions as before (Table 1, Column 3) with the notable exception that women's stated son preference is no longer statistically significant. This supports the conclusion that women are less able than men to use sex-selective abortions when their husband has no preference for sons.

[Table 1 about here]

\subsection{Sex-Selective Infant Mortality}

Parents who were forced to accept the birth of an unwanted daughter may decrease the odds of her surviving via sex-selective neglect. As infants are very frail, small neglects, such as taking longer to treat diarrhoea or a fever, may lead to death. Those small neglects may easily go unnoticed by household members other than the main care-giver, who is usually the mother. We thus argue that sex-selective infant mortality is more likely to occur in households in which the mother alone has a son preference, as in households in which the father has a son preference, sex-selective abortion will have been sought, as it is the most cost-effective method to engineer sex-ratio.

Starting with simple descriptive statistics, we note that the relative risks of dying in infancy - the ratio of boys on 1000 girls dying in infancy - are particularly biased toward girls when their mother prefers sons, followed by when both parents prefer for sons and, then, when only the father prefers sons. It is, however, normal in households where none prefer sons (Table 2). Hence, the influence of the fathers' stated son preference on infant survival appears to be much smaller than the influence of the mothers'.

While these statistics are interesting, they cannot prove a causal link between mothers' and fathers' stated son preference and girls' lower odds of surviving infancy. For this, we 
need to turn to regression analysis.

The results are presented in Table 3 - Probit coefficient (Column 1) and marginal effects (Column 2) - and Table 4 - predicted probability to die in infancy. In households where only the father has a preference for sons, the relative mortality risk of boys and girls is normal (1183 boys, rather than the American norm of 1200 , to every 1000 girls). However in all other household types, girls are at a higher relative risk of dying than what should be the case without discrimination. The relative mortality risk is particularly unfavourable in households where only the mother has a preference for sons, with girls being twice more at risk of dying during infancy than boys.

[Tables 2 to 4 about here]

\section{Conclusion}

Our results show a far more interesting and complex dynamic between spouses in the exercise of son preference, than has been recognized in the literature. The literature on son preference generally focuses on women's stated preferences. While it is widely recognized that the fathers' preferences matter, it is typically assumed that these preferences will be fully captured in women's responses and behaviour - as women are pressured to comply with their husbands' preferences.

Our findings indicate that fathers play a stronger role in decisions to abort. If they have lower son preference than their wives, they often seem to have a veto on the decision to abort. We argue that this veto comes from men's control over financial resources and limited female mobility since money to pay for the ultrasound and the capacity to go to an abortion clinic are both necessary to implement a sex-selective abortion. Our results also show that for households in which the husband has a stronger son preference than his wife, the woman may be coerced into having an abortion. 
We also find that if women have higher son preference than their husbands, they are able to manipulate their child-care towards achieving their preferences. Since women are the primary care-givers for children, fathers may not be able to stop their wife to eliminate unwanted daughters. While our data show that women have difficulties to obtain a sexselective abortion without their husband's consent, they also show that women are able to sex-selectively neglect daughters, leading to a higher girl mortality rate in households where only the mother has a stated son preference.

The results shed light on the importance of communication/bargaining in the household. Many decisions, such as sex-selective abortions or sending children to school, are likely to be discussed among adult household members. Hence, while many studies focus on women's preference and characteristics to explain children's outcomes and well-being, this study shows that this leaves out an important decision-maker and influential person, the father. More care should be given in collecting data and analysing fathers' role in decisions regarding their children as well as on how the bargaining process take place in households where the couple disagrees.

Our findings have an important implication for policy-makers in India and in other countries where son preference has led to skewed sex ratios. Focusing on banning sex-selective abortions will not eliminate the problem of imbalanced sex-ratio. While sex-selective abortions have made it easier to eliminate unwanted daughters, our results show that some mothers - and also very likely fathers if abortions were to become infeasible — are willing to sex-selectively neglect their daughters to death. A solution must thus include a change in people's preference.

\footnotetext{
${ }^{1}$ Many of these reasons to prefer sons are also an artifact of son preference. For example, the high status enjoyed by mothers of son increases the utility of having sons, but the reason why having a son increases women's status is because of the ingrained son preference in the community. Similarly, the desire to have a son to inherit the ancestral land comes from the tradition that deprives women from land ownership.
} 
${ }^{2}$ If a child is to be neglected to death, it is rational to do so as early as possible so as to limit unnecessary investment - such as time and food - on the child and to limit emotional attachment. It is also easier to conceal infanticide and blatant neglect early in life as the mortality risk is at its highest; hence our focus on infant mortality.

${ }^{3}$ The relevant questions in NFHS-3 are: "If you could go back to the time you did not have any children and could choose exactly the number of children to have in your whole life, how many would that be?" and "How many of these children would you like to be boys, how many would you like to be girls and for how many would it not matter?".

${ }^{4}$ It is common in the literature to look at the sex-ratio of the last birth while studying sex-selective abortions. Focusing on the last birth helps deal with issues we will discuss later on. It should however be kept in mind that the sex-ratio of the last birth is an inflated measure of the level of gender imbalance in the population as many parents are willing to let faith determines the gender of their first born (Jha et al. 2006), parents are more likely to stop childbearing after the birth of a son (Arnold et al. 2002) and some parents may shorten birth spacing after the birth of a girl, in the hope of having a son (Arnold et al. 1998).

5 Descriptive statistics for the dependent and the independent variables are presented in Online Appendix B while variables' descriptions are available in Appendix C.

${ }^{6}$ In a model explaining the percentage of boys desired if the respondent could start over his/her fertility history, estimated using OLS and controlling only for the sex-ratio of ever born children and the gender of the last child, we conclude, for both men and women, that the sex-ratio of ever born children is a significant determinant, but not the gender of the last child in the case of the men's equation; while, in the case of women, having had a boy as a last birth reduces the percentage of boys desired (results available on request).

${ }^{7}$ Given the dichotomous nature of the dependent variable, a Probit model would have been more appropriate. However, the use of OLS has the advantage of allowing us to interpret directly the constant. As a robustness check the model was also estimated using Probit. The main conclusions remain (results available on request). ${ }^{8}$ It is however possible that parents who had a daughter but are desperate for a son, may end up with very short birth spacing. 


\section{References}

Arnold, F., M.K. Choe, and T.K. Roy (1998) 'Son preference, the family-building process and child mortality in India' Population Studies 52(3), 301-315.

Arnold, F., S. Kishor and T.K. Roy (2002) 'Sex-selective abortions in India' Population and Development Review 28(4), 759-785.

Balsara, S.L., J.A. Faerber, N.B. Spinner, and C. Feudtner (2013) 'Pediatric mortality in males versus females in the United States, 1999-2008.' Pediatrics 132(4), 631-638.

Becker, G.S. (1960) An economic analysis of fertility (Princeton, N.J.: Princeton University Press).

Becker, G.S., and K.M. Murphy (2000) Social economics: market behavior in a social environment (Cambridge: Harvard University Press).

Booth, B.E., M. Verma, and R.S. Beri (1994) 'Fetal sex determination in infants in Punjab, India: Correlations and implications.' British Medical Journal 309(6964), 1259-1261.

Das Gupta, M. (1987) 'Selective discrimination against female children in rural Punjab, India.' Population and Development Review 13(1), 77-100.

Das Gupta, M., J. Zhenghua, L. Bohua, X. Zhenming, W. Chung, and B. Hwa-Ok (2003) 'Why is son preference so persistent in East and South Asia? a cross-country study of China, India and the Republic of Korea.' The Journal of Development Studies 40(2), 153187.

Drew J.S., W.T. London, E.D. Lustbader, J.E. Hesser and B.S. Blumberg (1978) "Hepatitis B virus and sex-ratio of offspring" Science 21(August), 687-692.

Dyson, T., and M. Moore (1983) 'On kinship structure, female autonomy, and demographic behavior in India.' Population and Development Review 9(1), 35-60. 
Ganatra, B., S. Hirve, and V.N. Rao (2001) 'Sex-selective abortion: Evidence from a community-based study in Western India.' Asia-Pacific Population Journal.

George, S. M. (1997) 'Female Infanticide in Tamil Nadu, India: From Recognition Back to Denial?' Reproductive Health Matters 5(10), 124-32.

IIPS (2007a) National Family Health Survey (NFHS-3), 2005-06: India: Volume I. (Mumbai: IIPS).

IIPS (2007b) National Family Health Survey (NFHS-3), 2005-06: India: Volume II. (Mumbai: IIPS).

Iyer, S. (2002) Demography and Religion in India. (Oxford: Oxford University Press).

Jha, P., R. Kumar, P. Vasa, N. Dhingra, D. Thiruchelvam and R. Moineddin (2006) 'Low Maleto-Female Sex Ratio of Children Born in India: National Survey of 1.1 Million Households.' The Lancet 367(9506), 211-18.

Ronsmans, C., and W.J. Graham (2006) 'Maternal mortality: Who, when, where, and why.' The Lancet 368(9542), 1189-1200.

Sinha, K. (2012) 'Despite abortion laws, 66\% of Indians use unsafe route.' The Times of India. January 19, 2012.

Vella, S. (2005) Low Fertility And Female Discrimination In South India (New Delhi: Sage Publication).

Waldron, I. (1998) Factors determining the sex-ratio at birth (New York: Department of Economics and Social Affairs, Population Division). 
Table 1: OLS: Sex-ratio and gender of the last child: Influence of parents' stated son preference

\begin{tabular}{lccc}
\hline & Sex-ratio & Male & $\begin{array}{c}\text { Male } \\
(2004-2006)\end{array}$ \\
\hline Both Parents Prefer Sons & $0.0970 * * *$ & $0.0819 * * *$ & $0.0826 * * *$ \\
& $(0.0060)$ & $(0.0156)$ & $(0.0230)$ \\
Mother Only Prefers Sons & $0.0695 * * *$ & $0.0577 * * *$ & 0.0339 \\
& $(0.0052)$ & $(0.0137)$ & $(0.0208)$ \\
Father Only Prefers Sons & $0.0526 * * *$ & $0.0705 * * *$ & $0.0619 * * *$ \\
& $(0.0052)$ & $(0.0132)$ & $(0.0197)$ \\
Constant & $0.5083 * * *$ & $0.5211 * * *$ & $0.5166 * * *$ \\
& $(0.0024)$ & $(0.0058)$ & $(0.0087)$ \\
\hline Observation & 33,641 & 11,793 & 5,227 \\
R-squared & 0.0111 & 0.0046 & 0.0036 \\
\hline
\end{tabular}

Notes: Standard errors, in parenthesis, are adjusted for cluster at the primary sampling unit level. $* * *, p$-value $<0.01, * * p$-value $<0.05$ and $* p$-value $<0.10$. For ease of interpretation, OLS was used for all models. 
Table 2: Relative mortality rate - number of boys dying in infancy per 1000 girls' infant death - by mothers' and fathers' stated son preference.

\begin{tabular}{|c|c|c|}
\hline & \multicolumn{2}{|c|}{ Mother } \\
\hline & No Son Preference & Son Preference \\
\hline $\begin{array}{l}\text { No Son Preference Son } \\
\text { D्ञ } \\
\text { 壱 Preference }\end{array}$ & $\begin{array}{c}1204 \\
(5,636) \\
914 \\
(1,749)\end{array}$ & $\begin{array}{c}755 \\
(1,570) \\
830 \\
(1,093)\end{array}$ \\
\hline
\end{tabular}


Table 3: Probit: Infant survival ( $<1$ year).

\begin{tabular}{|c|c|c|c|c|c|}
\hline & $\begin{array}{c}\text { (1) } \\
\text { Coefficient }\end{array}$ & $\begin{array}{c}(2) \\
\text { Marginal } \\
\text { Effect }\end{array}$ & & $\begin{array}{c}\text { (1) } \\
\text { Coefficient }\end{array}$ & $\begin{array}{c}(2) \\
\text { Marginal } \\
\text { Effect }\end{array}$ \\
\hline \multirow[t]{2}{*}{ Rural } & 0.0592 & 0.0076 & Media: At Least Once a Week & -0.0888 & -0.0114 \\
\hline & $(0.0561)$ & $(0.0071)$ & & $(0.0551)$ & $(0.0078)$ \\
\hline \multirow[t]{2}{*}{ Religion: Christianity } & -0.0738 & -0.0094 & Age (in Years) & $0.0151^{* * *}$ & $0.0019^{* * *}$ \\
\hline & $(0.1087)$ & $(0.0140)$ & & $(0.0047)$ & $(0.0007)$ \\
\hline \multirow[t]{2}{*}{ Religion: Islam } & 0.0636 & 0.0081 & Nuclear Household & 0.0600 & 0.0077 \\
\hline & $(0.0706)$ & $(0.0094)$ & & $(0.0454)$ & $(0.0056)$ \\
\hline \multirow[t]{2}{*}{ Religion: Other } & 0.0194 & 0.0025 & Twin & $-0.8261 * * *$ & $-0.1056^{* * *}$ \\
\hline & $(0.1247)$ & $(0.0160)$ & & $(0.1532)$ & $(0.0281)$ \\
\hline \multirow[t]{2}{*}{ Scheduled Caste } & -0.0056 & -0.0007 & Previous Birth $<12$ months & $-0.4351 * * *$ & $-0.0556 * * *$ \\
\hline & $(0.0679)$ & $(0.0087)$ & & $(0.1226)$ & $(0.0189)$ \\
\hline \multirow[t]{2}{*}{ Scheduled Tribe } & -0.0178 & -0.0023 & Antenatal Care & $0.1011^{*}$ & $0.0129^{*}$ \\
\hline & $(0.0899)$ & $(0.0115)$ & & $(0.0588)$ & $(0.0075)$ \\
\hline \multirow[t]{2}{*}{ Backward Caste } & 0.0421 & 0.0054 & Mother's BMI & $-0.0204 * * *$ & $-0.0026^{* *}$ \\
\hline & $(0.0601)$ & $(0.0075)$ & & $(0.0069)$ & $(0.0010)$ \\
\hline \multirow[t]{2}{*}{ Don't Know Caste } & 0.0949 & 0.0121 & Female & 0.0406 & 0.0052 \\
\hline & $(0.1363)$ & $(0.0177)$ & & $(0.0563)$ & $(0.0072)$ \\
\hline \multirow[t]{2}{*}{ Wealth Quintile: Poorest } & -0.0232 & -0.0030 & Both Parents Prefer Sons & -0.0471 & -0.0060 \\
\hline & $(0.0764)$ & $(0.0096)$ & & $(0.0918)$ & $(0.0118)$ \\
\hline \multirow[t]{2}{*}{ Wealth Quintile: Poorer } & 0.0198 & 0.0025 & Both Parents Prefer Sons * Female & -0.0355 & -0.0045 \\
\hline & $(0.0673)$ & $(0.0087)$ & & $(0.1420)$ & $(0.0187)$ \\
\hline \multirow[t]{2}{*}{ Wealth Quintile: Richer } & $0.1990 * * *$ & $0.0254 * *$ & Mother Only Prefers Sons & $0.1878 * *$ & $0.0240 *$ \\
\hline & $(0.0676)$ & $(0.0108)$ & & $(0.0936)$ & $(0.0125)$ \\
\hline \multirow[t]{2}{*}{ Wealth Quintile: Richest } & $0.3235^{* * *}$ & $0.0414^{* * *}$ & Mother Only Prefers Sons * Female & $-0.3822 * * *$ & $-0.0489 * * *$ \\
\hline & $(0.0912)$ & $(0.0151)$ & & $(0.1266)$ & $(0.0184)$ \\
\hline \multirow[t]{2}{*}{ Mother's Education (in Years) } & $0.0184 * * *$ & $0.0024 * *$ & Father Only Prefers Sons & -0.0192 & -0.0025 \\
\hline & $(0.0066)$ & $(0.0009)$ & & $(0.0839)$ & $(0.0108)$ \\
\hline \multirow[t]{2}{*}{ Father's Education (in Years) } & 0.0065 & 0.0008 & Father Only Prefers Sons * Female & 0.0440 & 0.0056 \\
\hline & $(0.0061)$ & $(0.0008)$ & & $(0.1273)$ & $(0.0163)$ \\
\hline \multirow[t]{2}{*}{ Mobility: Allowed to Go Alone } & $0.0916^{*}$ & $0.0117^{*}$ & Constant & $1.2247 * * *$ & \\
\hline & $(0.0509)$ & $(0.0071)$ & & $(0.1994)$ & \\
\hline State's Fixed Effects & & & & Yes & Yes \\
\hline Observations & & & & 11,204 & 11,204 \\
\hline
\end{tabular}

Notes: The marginal effect has been obtained holding all continuous variables at their mean, for dummy variables taking the value of the most likely outcome and taking the case of a household where both parents prefer sons. Standard errors, in parenthesis, are adjusted for cluster at the primary sampling unit level. ***, p-value $<0.01, * * \mathrm{p}$-value $<0.05$ and $* \mathrm{p}$-value $<0.10$. 
Table 4: Predicted infant mortality rate per 100 live birth by gender and family type

\begin{tabular}{lccc}
\hline & Boys & Girls & Boys/Girls \\
\hline Both Parents Prefer Sons & 6.64 & 6.57 & 1011 \\
& {$[3.84-9-44]$} & {$[3.33-9.81]$} & \\
Mother Only Prefers Sons & 4.11 & 8.12 & 506 \\
& {$[2.08-6.14]$} & {$[4.94-11.31]$} & \\
Father Only Prefers Sons & 6.28 & 5.31 & 1183 \\
& {$[3.60-8.96]$} & {$[2.64-7.97]$} & \\
None Prefers Sons & 6.05 & 5.58 & 1084 \\
& {$[4.02-8.08]$} & {$[3.63-7.53]$} &
\end{tabular}

Notes: The predicted probability have been obtained holding all continuous variables at their mean and for dummy variables taking the value of the most likely outcome. Confidence interval at the $5 \%$ level are in brackets. 
Figure 1: The spatial distribution of gender discrimination Panel A: Ratio of boys on girls aged 6-14 attending school Panel B: Ratio of the number of vaccines received by boys to

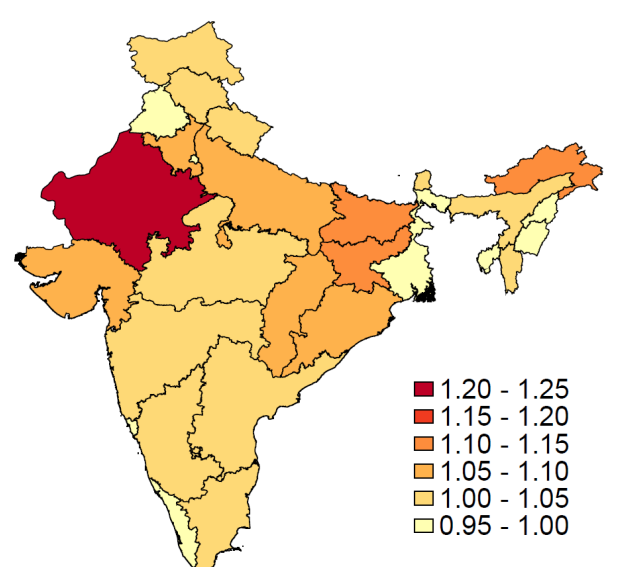

Panel D: Ratio of boys on girls who died during infancy

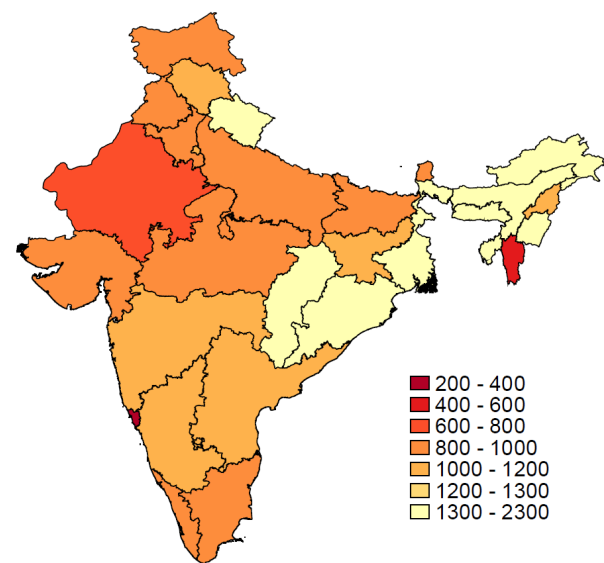

that received by girls less than 5 years old

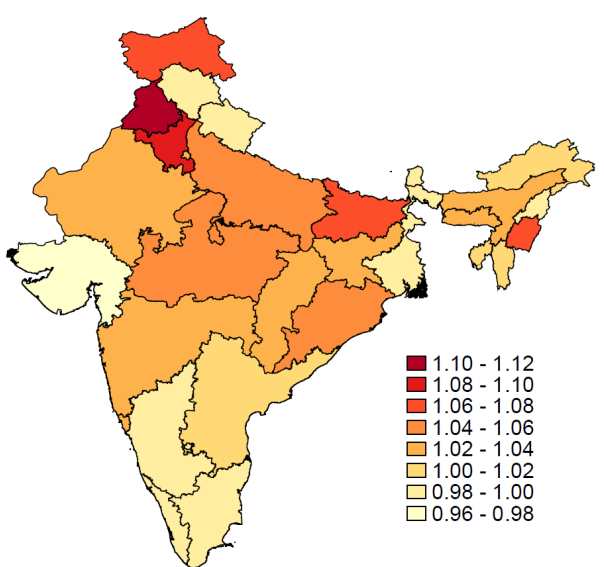

Panel E: Women's stated son preference

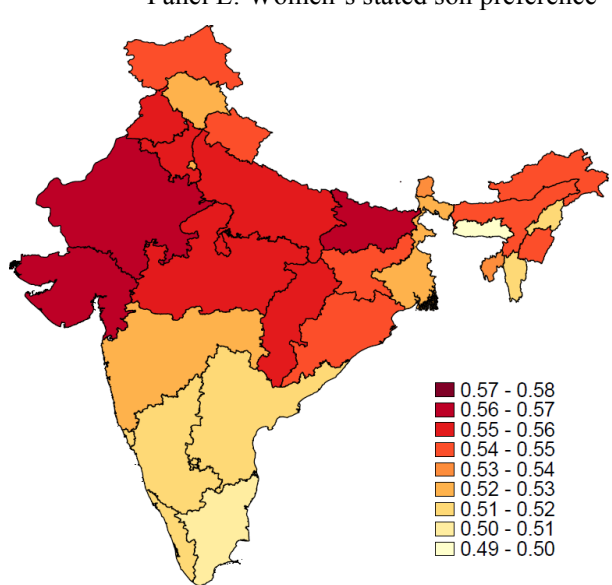

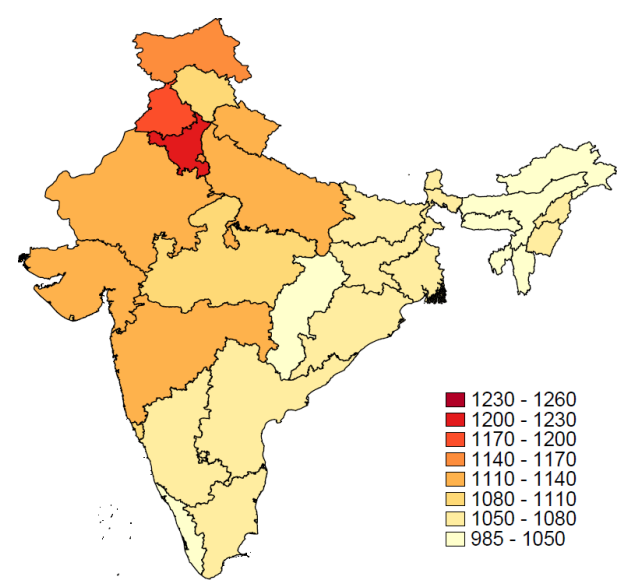

Panel F: Men's stated son preference

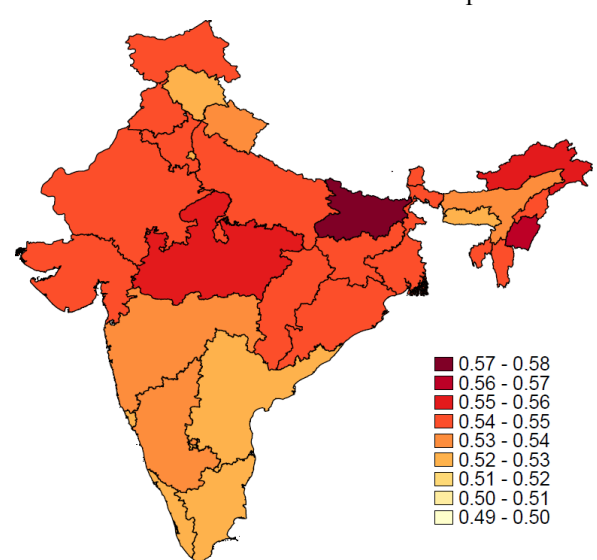

Source: For schooling, vaccination, infant mortality and stated son preference: NFHS-3 (authors' calculation). For sex-ratio: 2011 Indian Census (authors' calculation. 